\title{
Chapter 14 \\ An Effective Approach to Mainstreaming DRR and Resilience in La Paz, Mexico
}

\author{
Juan Carlos Vargas Moreno, Enrico Ponte, Sophia Emperador \\ and Marcela Orozco Noriega
}

\begin{abstract}
This chapter proposes a methodology to delineate strategic priorities and identify specific locations for disaster risk management tactics that integrate a geospatial approach with qualitative and quantitative analysis. This methodology was applied to a case study developed in the mid-sized city of La Paz, capital of Baja California Sur, Mexico and serves as an example of an integrative mainstreaming disaster risk management approach. The mainstreaming process was developed in four distinct phases (technical, institutional, social and financial) that engage a diverse range of stakeholders, representing a broad range of professional knowledge and experience. This study presents the first spatial resilience evaluation in Mexico and details how a mainstreaming approach can be integrated with technocratic methods to better dimension risk and provide decision makers with a versatile and effective multifaceted tool tailored to local needs.
\end{abstract}

Keywords Mainstreaming - Geospatial analysis - Resilience strategies - Decision makers support $\cdot$ Disaster risk reduction

\subsection{Introduction}

The economic, social and environmental impacts of disasters will increase in the coming decades as the effects of climate change further exacerbate this trend. Global economic losses due to adverse natural events between 1980 and 2014 have

J.C. Vargas Moreno $\cdot$ E. Ponte $(\bowtie) \cdot S$. Emperador $\cdot$ M. Orozco Noriega

GeoAdaptive LLC, 250 Summer Street. First Floor, 02210 Boston, MA, USA

e-mail: eponte@geoadaptive.com

J.C. Vargas Moreno

e-mail: jcvargas@geoadaptive.com

S. Emperador

e-mail: semperador@geoadaptive.com

M. Orozco Noriega

e-mail: arqmarcelaorozco@gmail.com

(C) The Author(s) 2017

M. Tiepolo et al. (eds.), Renewing Local Planning to Face Climate

Change in the Tropics, Green Energy and Technology,

DOI 10.1007/978-3-319-59096-7_14 
been estimated at US\$4.2 trillion (Munich Re 2015). The occurrence of extreme weather patterns such El Niño of 2015/2016, one of the strongest recorded, and the World Bank's estimate of 100 million people in extreme poverty by 2030 (World Bank 2016) highlight the dangerous confluence of conditions that are predicted to take place in the near term.

These circumstances underscore why the integration of risk reduction, climate change adaptation and resilience strategies must become an urgent priority as a means to address a growing urban risk in a more effective and efficient manner.

In 2012, the World Bank (WB) presented the 'Sendai Report: Managing Disaster Risks for a Resilient Future' outlining 4 "Priorities for action" to mainstream or integrate Disaster Risk Management (DRM) and disaster and climate risk across WB activities in developing countries. This report was produced using data from 2012-2015 to assess the general progress in mainstreaming activities across WB efforts, such as: (i) in lending operations; (ii) in strategies; (iii) across global practices; and (iv) through investment in key dimensions of DRM; and (v) through partnerships.

The WB has made encouraging progress on the mainstreaming of DRM, both in terms of the quantity and type of operations. For example, annual financial contributions to DRM increased from US\$3.7 billion in 2012 to US\$5.7 billion in 2015. The mainstreaming approach has promoted a more favorable balance between ex ante risk management and post-disaster response financing.

Effective DRM requires attention at every step of the cycle: from disaster preparedness to resilient recovery. The WB has invested in developing multi-disciplinary expertise in key dimensions of DRM, from risk modeling and assessment, early warning and weather and climate services, and risk financing and insurance. Under the Global Practice for Social, Urban and Rural Development, and Resilience's (GSURR) leadership, the WB has advanced specialized expertise and operational capacity to offer services in these areas to member countries. The Global Facility for Disaster Reduction and Recovery (GFDRR) has supported progress through specialized thematic technical teams, as well as grant funding that has informed the design of projects and provided support for investment operations.

New tools and methods are improving how disaster risks are identified and addressed. For example, the Innovation Lab program, hosted by GFDRR, has promoted open data platforms, citizen-led data collection with smart-phones, and other innovative approaches utilizing remote sensing and geospatial hazard datasets. Such tools have increasingly been used to support policy decisions and investment allocation. The incorporation of hazard data, as well as the consideration of future climate change impacts, has increasingly informed investment projects that might otherwise fail to account for extreme events.

This chapter presents an innovative methodology that uses strong quantitative and qualitative approaches, which were informed by a robust mainstreaming process and organized in four steps. As part of this process, a participatory phase was developed involving a variety of stakeholders representing a range of professional expertise, interests and local knowledge, comprised of representatives from: multilevel government agencies, NGOs, members from the private sector, academia, 
and civil society. The application of the methodology is presented as a case study developed in the city of La Paz (Baja California Sur, Mexico).

\subsubsection{Mainstreaming: A State of the Art Approach}

With the increase of disaster related risk, particularly in urban areas, there is growing consensus among experts that the key to the lessening of risk lies in the 'mainstreaming' of disaster risk reduction into development planning and policy. The Urban Agenda recently presented at the HABITAT III Conference in Quito underlined the relevance and crucial nature of such approach, as a means "... to strengthen the resilience of cities and human settlements, using mainstreaming holistic and data-informed disaster risk reduction and management at all levels, reducing vulnerabilities and risk, especially in risk-prone areas of formal and informal settlements" (UN-Habitat 2016).

The term "mainstreaming" is derived from the concept of how small, isolated tributaries flow into the larger main-stream of a river, a seamless integration of disparate flows into a larger whole (Pelling and Holloway 2006: 16). Hence "mainstreaming risk reduction" describes a process that fully incorporates and integrates the efforts of disaster risk reduction (DRR) into larger relief efforts and development policy (La Trobe 2005). This approach aims to radically expand and enhance DRR so that it is incorporated into normal practice, and fully institutionalized within an agency's relief and development agenda. Essentially, this process merges the key principles of DRR with development goals, governance arrangements, institutional policies and practices.

When put into practice, mainstreaming requires an analysis of how potential hazard events could affect the performance of policies, programs and projects, on the other hand, it should also consider the impact of these on the vulnerable landscapes. Results from these analyses can help inform risk sensitive development, which is now widely recognized as a critical component to achieve sustainable development.

The mainstreaming process must also include or consider the effects of climate change, and incorporate additional priority interventions as appropriate. This process requires investing in climate change monitoring and forecasting (both science and policy related) as part of broader national efforts. Additional interventions such as budgeting and financing for adaptation include the integration of adaptation into national systems and the leveraging of special funding sources and modalities. Policy interventions can intervene at different levels including general measures that are reviewed with a climate lens, as well as adaptation-specific measures (UNDP-UNEP 2011).

Effective mainstreaming of DRM across multiple key sectors is vital for resilient development "because DRM is not a sector in itself, but a process to protect development progress, reduce losses and support growth" (Mackay and Bilton 2003). This process is embedded in the day-to-day operations of national and local organizations, across strategic sectors, and completed with specific resources (human, financial, technical, material, knowledge) allocated to manage potential risks. 
The introduction of mainstreaming efforts can occur at all levels of governance, from its insertion into development plans, processes and initiatives at the local level (e.g. city master plans or individual infrastructure projects), to efforts at the sub-national and national levels. Risk management principals can also be mainstreamed within decision-making processes, legislation, regulations, organizational protocols and subsidy regimes. Regardless of the level of governance or administrative avenue, mainstreaming largely takes place within the core sectors related to development activities used by most governments worldwide. These include agriculture, transportation, utilities, housing, health and education, amongst others.

As a social justice-led approach to policy making, mainstreaming allows for the integration of equal opportunity principles, strategies and practices into the everyday workings of the government and other public bodies. It has three key characteristics: it is a deliberate process; there are multiple routes and/or outputs that can be targeted (e.g. policies, plans and legislation); and it should take place across multiple levels of government.

According to this definition and characterization of mainstreaming, the following three purposes can be defined:

- To make certain that all the development programs and projects are designed with evident consideration for potential disaster risks (La Trobe 2005). Currently, future risks are evaluated through separate processes, when it should be done concurrently. Therefore, there is often a basic lack of technical capacity for understanding, evaluating and acting on risk information (Oates et al. 2011).

- To make certain that all the development programs and projects do not inadvertently increase vulnerability to disaster in all sectors (social, physical, economic and environment), influence the existing development agenda (Jahan 1995) or modify existing laws and other legal provisions, as defined in the Hyogo framework of action in 2005.

- To make certain that all disaster relief and rehabilitation programs and projects are designed through a deliberate process that takes place across multiple levels of government (Pervin et al. 2013; Bettencourt et al. 2006). Currently, DRM is seen as being 'outside' of sectoral development, having low priority in core sectors, and lacking the appropriate national legislation (Schipper and Pelling 2006; Pelling and Wisner 2009).

The decentralization of DRM for local authorities is a critical element of good governance. However this is often undermined by constraints due to local institutional capacity, financing difficulties, challenges with cross-government coordination and low levels of citizen participation in risk-management activities (William 2011). Experience has shown that in order for decentralization to be effective other supporting aspects are needed, such as: "strong national leadership on DRM; mechanisms to enforce DRM policies; high levels of public awareness about risks and risk reduction; adequate technical capacity to undertake risk-reduction actions; and incentives that create strong political interest in risk-informed planning" (Scott and Tarazona 2011). 


\subsection{Methodology}

Creating a clear 'vision' of mainstreaming approach has proved to be difficult for governments and other agencies around the World. Mainstreaming is a complex process that requires guidance by technical specialists and leaders. This can be hampered by capacity of local sectoral staff, weak institutional mandates for mainstreaming, and political pitfalls (Bahadur and Tanner 2013). In addition, the process can be obstructed by the grouping and compartmentalization of funding streams for DRM and climate change development, inadequate interest from the private sector, and the scarcity of estimates for the cost of mainstreaming. These conditions make it difficult to obtain financing for the application of mainstreaming (Becker-Birck et al. 2013). In the end, solutions and strategies are needed to ensure that sectors no longer operate without a clear acknowledgement of risk and its impact on development. This requires strong political leadership and agreement between the different stakeholders (Harris and Bahadur 2014).

These challenges serve as the starting point from which GeoAdaptive has developed its methodology.

As a means to reduce risk and encourage the development of prosperous, equitable and sustainable societies, GeoAdaptive has applied a specific mainstreaming methodology which refers to processes that include the results of risk assessments and climate change adaptation practices within current planning documents at all levels of government (e.g. local: city master plans; regional: State development plans; and national: five-year plans). Through this approach diverse risk profiles are developed, which indicate specific areas for investment and help define strategic priorities.

GeoAdaptive incorporates a robust approach that divides mainstreaming into four phases providing planners and decision makers a tool that allows them to understand climate risk and to run a cost-benefit analysis of the potential implementation of specific measures and strategies. These four phases are described as follows:

- Technical mainstreaming. The goal of this phase is to validate the results obtained during the previous risk analysis and to train local experts to best use the information that has been collected. Through this phase different risk profiles are considered and merged with accessible and timely information on the economic returns of risk-informed decisions and risk-reducing investments. Within this phase GeoAdaptive works with the technical team from the local government and other key stakeholders to interpret the information collected and the analytical results. As part of these efforts training is provided in disaster related topics, as well as other skills related to the improvement of communications within the local administration (ADPC 2010). In addition, officials are provided training in public participatory processes and multi-stakeholder dialogue that help resolve conflict over development priorities. Training programs provide the relevant risk information for local needs, encourage the respect and utilization of indigenous knowledge and promote traditional practices of coping with disaster 
risks (UNISDR 2015). A capacity assessment helps formulate a development strategy that will be necessary to address deficiencies, and optimize existing capacities. Within this phase GeoAdaptive also defines a first list of priority actions and recommendations with the purpose of identifying structural and non-structural resilience measures, the economic viability of future investments and the specific risks and benefits related to the implementation of these measures. This process is conducted by GeoAdaptive's technical team of experts, in coordination with local or national task groups, or units for disaster risk reduction (DRR).

- Institutional mainstreaming. Through this phase GeoAdaptive develops a detailed analysis to prioritize the most powerful actions and strategies and defines their implementation. The methodology supports the development of government-based decision processes that are based on local laws, consensus oriented, participatory, efficient, equitable, transparent and accountable. GeoAdaptive aims to increase the culture and effective practice of DRR amongst local institutional stakeholders ensuring that the local and national authorities can function adequately during risk situations. Considering that a lack of coordination and cooperation is still one of the key obstacles to achieving an effective mainstreaming process, GeoAdaptive's team encourages the active involvement of different stakeholders in the internal mainstreaming process, including the private sector and non-governmental groups (e.g. environmental or community groups). National legislatures can provide an overarching framework for risk reduction and can enable risk reduction strategies in the key ministries (ADPC 2010). Regional governments with powers to draw up locally enforceable legislation can often issue appropriate executive orders, ordinances and other directives to require departments and agencies, private companies, voluntary groups and citizens in its jurisdiction to carry out certain risk reduction actions (ADPC 2010). Aligning local and national legislation, policies and practices with global frameworks for DRR and sustainable development (e.g. HFA, MDGs, and Habitat Agenda) can generate support from international agencies for local DRR initiatives, in the form of technical advice and/or financial resources. The institutional structure should strengthen the horizontal and vertical integration of DRR between different levels of government, between various key agencies, between other stakeholders (e.g. civil society, private sector, academia, etc.) and between neighboring localities (Benson 2009). Multi-sector and multi-level communication and cooperation seems more likely to happen in many countries when the highest level of executive power, such as the Prime Minister or President oversees the coordination of DRM (Benson 2009). Many countries have established disaster management committees, with members representing different economic sectors and interests, to facilitate the mainstreaming process.

- Educational mainstreaming. GeoAdaptive's approach aims to improve the integration of science policy with risk reduction and adaptation strategies. The participatory nature of our approach amongst universities, the private sector and representatives from community organizations provides GeoAdaptive with 
expert knowledge on local conditions, the opportunity to validate analytical results, to identify site-based adaptation strategies and to raise local awareness. Overall this phase begins with stakeholder validation of the results from the organizational and institutional mainstreaming phases (e.g. scenario results, forecasts from prior assessments, etc.). This mainstreaming phase is developed through different workshop, training activities and meetings, which are facilitated across the all four phases of a project.

- Financial mainstreaming. Most local governments have yet to incorporate DRR and resilience strategies into their yearly budget, although some do have contingency or calamity fund for emergency response (ADPC 2010). Moreover, in most cases, local governments are expected to dedicate budget line for DRR and resilience from existing budgets (ADPC 2010). Regardless, local government also need to explore other sources of disaster-related funding. The Sendai Framework encourages countries to mainstreaming disaster risk into their macroeconomic strategies and public finances. Integrating the mainstreaming process is a central part of building resilience, as a means of protecting and guaranteeing the livelihood of individuals and businesses, as well as the operation of the public sector institutions. To strengthen the country's economic and fiscal resilience, governments should integrate disaster risk in public finance, including the development of risk-sensitive investments and risk financing mechanisms (UNISDR 2016). The capacity of countries to develop a sound economic analysis on the benefits of DRR is a central support for investment and policy decisions conducting to resilience. GeoAdaptive's process is developed to help decision-makers better identify the best funding mechanisms for the different actions and strategies prioritized in the institutional mainstreaming phase.

Departing from the results obtained by the four different mainstreaming phases, GeoAdaptive's team can evaluate the benefits of the strategies and measures developed in the prior phases. The resulting recommendations must be complemented with appropriate monitoring systems and should enable the development of strategies at the planning, execution and evaluation stages. However, monitoring mechanisms (particularly in developing countries) are often ad hoc, inconsistent, lacking transparency, or non-existent. This presents a challenge to policy-makers seeking to institutionalize risk-informed planning through national legislation. Therefore, GeoAdaptive's final validation is obtained through the identification of goals from local authorities, an evaluation of the impacts and the development of a monitoring and evaluation process. These goals are organized in four groups:

- Implementing supportive policies: Within institutional mainstreaming GeoAdaptive recognizes the importance of strengthening political commitments, the implementation of policy and institutional frameworks that incorporate disaster risk assessment, facilitate the investment of requisite resources, and strengthen the social capital of vulnerable communities. 
- Utilizing local experience and wisdom in risk assessment: GeoAdaptive recognizes the importance of citizen's experience of disasters and mitigation actions. Hence, the incorporation of citizen's experience of disaster and mitigation actions. Hence, the incorporation of traditional and local knowledge during our participative approach ensures that the process is responsive to the local conditions of the communities at risk, thereby enhancing its effectiveness.

- Basing risk assessment on information management: Starting with a risk assessment process that considers local information and data, we recognize the basic governance responsibility of providing information on potential and actual risks.

- Ensuring professional management of risk assessment systems: Ensuring professionalism in risk assessments requires investment in data, information and communication systems and in the development the requisite institutional and human capability to manage the process.

\subsection{La Paz, Case Study}

The following case study presents a pilot project that provided a rapid spatial analysis of the impact (both damages and losses) of hurricane Odile (September 15, 2014) on the Mexican municipality of La Paz. Hurricane Odile was the most intense tropical cyclone to affect the Baja California since 1976 (Fig. 14.1).

According to the National Center for Disaster Prevention (CENAPRED 2015) Odile caused six deaths, stranded 32,000 tourists and generated pecuniary damages close to MXN $\$ 12$ billion pesos (state-wide).

The study area focused on the urban extent of the municipality of La Paz, the capital of the state of Baja California Sur. Situated northwest of Mexico City, La Paz is situated in a bay on the southeastern portion of the Baja California Peninsula with an urban population of 215,178 residents (INEGI 2010). This coastal city is located in an arid and semi-desert landscape and is the civic, educational and commercial center of the region (Fig. 14.2). Although it's the primary center of government for the state, the economic drivers of the region are focused on tourism and commerce.

The proximity, geographic isolation, and economic and infrastructural interdependencies amongst the municipalities of $\mathrm{La} \mathrm{Paz}$ and Los Cabos generate an intrinsic relationship. This inter-reliant relationship was taken into consideration during the analytical phase and these results were integrated into the study as a means to identify resilience strategies at the regional level.

The analysis and final results summarized here form part of a larger effort: "Intervenciones estratégicas hacia un futuro resiliente en La Paz, Baja California Sur", developed with the support of the International Community Foundation (ICF) and the Inter-American Development Bank (IDB). 
Fig. 14.1 Damage caused by Hurricane Odile in La Paz, Mexico (Source www. lacrónica.com, mmspress.com.mx)
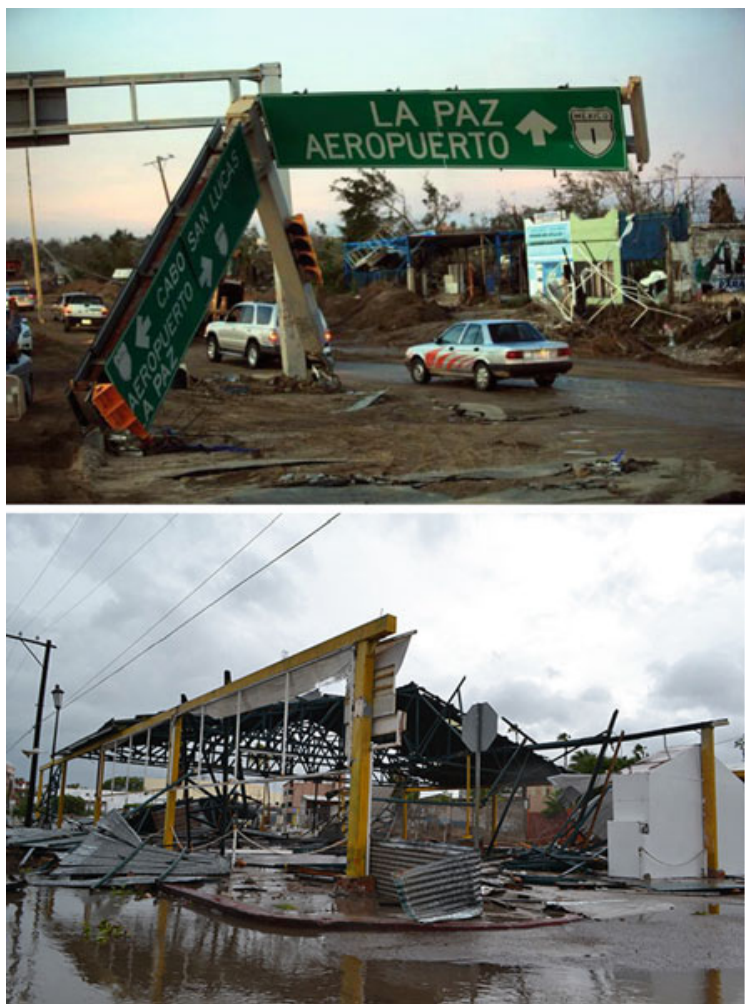

\subsubsection{Project Need}

The impact of Hurricane Odile underscored the need for a holistic and systematic review of the effects a large natural hazard could have upon the region and how the city could become more resilient from a physical, social, economic, and institutional perspective. The development of such assessment allowed city officials to rethink how they can adapt and prepare for the effects of climate change and natural hazards. This additional information can help move towards a new model of sustainable urban development that increases the city's regional competitiveness, while maintaining a high quality of life, for which La Paz is known. Within this context, the study evaluated the impacts caused by Hurricane Odile and provided an analysis of the capacities to prevent and respond to extreme events in $\mathrm{La} \mathrm{Paz}$, as a means to formulate strategies of resilience.

The study aims to: (1) assess the impact of Hurricane Odile and the city's capacity to cope with and respond to disasters, and (2) identify a series of strategic interventions that increase the long term resilience of the city.

Completed in a two part structure, the first part relied on geospatial assessment that identified the intensity of natural hazards (flooding, hurricanes, earthquakes, 


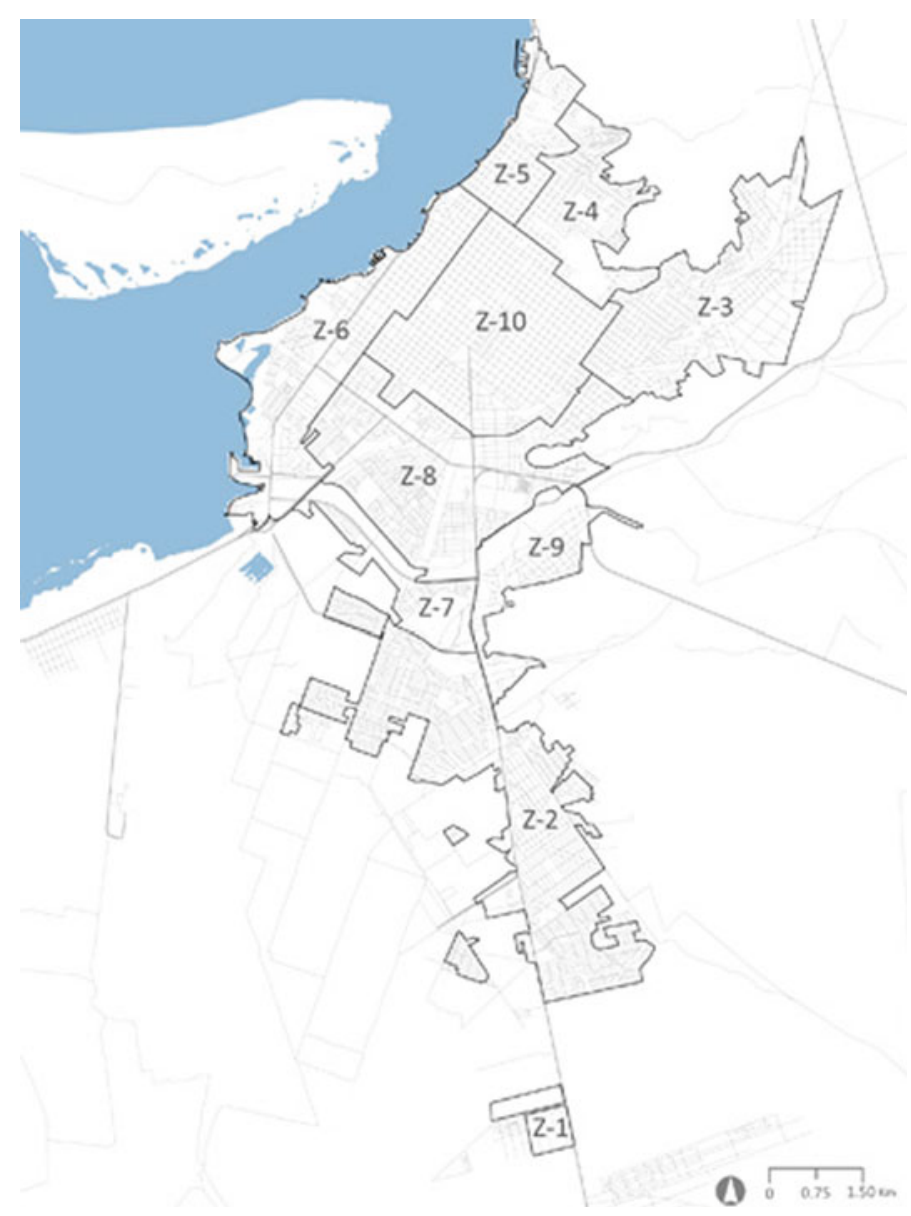

Fig. 14.2 Area of study: La Paz, Baja California Sur, Mexico (Source INEGI 2010), division of the study area into 10 zones

and landslides), and the effects of climate change (increasing temperatures, sea level rise) on the landscape, as well as the vulnerabilities and impacts to the city and its inhabitants. These assessments were taken from multiple sources, such as the studies conducted for the city of La Paz, as part of the IDB's Emerging and Sustainable Cities Initiative (ESCI), the risk atlas, as well as other official and academic reports. The corresponding results served as a comprehensive base for further analysis aimed to understand the underlying issues that exacerbate the vulnerability of the city and guide the delineation of actions to reduce these, while increasing the long-term welfare and well-being of the population.

The second part of the project focused on the spatial evaluation of the urban resilience post-natural disaster. As a pilot project the study lacked comparable references with respect to the evaluation method or with the development of 
recommendations. Therefore added value of this study lies in the introduction of the spatial dimensioning of the analysis and in the evaluation of both the constraints of social resilience and of the municipal infrastructure (Fig. 14.3).

The spatial evaluation allowed stakeholders to visualize and geographically identify the extent and intensity of multiple hazards, the vulnerability of the city's social institutions and infrastructure, as well as the overall impacts. Through this process, a first evaluation of spatial resilience was developed that specifically considered the city's management and adaptation capacity, the response actions and the reconstruction of diverse sectors. The resulting analysis allowed the definition of priorities and specific actions that have the potential to increase resilience in the city and generate a more sustainable future. The development of the resilience assessment was highly dependent on a participatory process, with contributions from local experts (national, state and local level). As a means to organize this component a "Resilience Committee" was formed, composed of key representatives from municipal, state and federal agencies, civil society, academia and the private sector. These select participants contributed with their knowledge, insight and experience throughout the project to validate data, evaluations and proposals prepared by the project team.

This chapter focuses on the second part of the study and the application of the geospatial resilience assessment and the participatory process that guided the identification and refinement of actions and resilience strategies. The overall process was guided by the following steps:

1. Evaluation (14.3.2). Resilience Analysis. The baseline evaluation of the city is the first step, comprised of a series of geospatial assessments that include: a

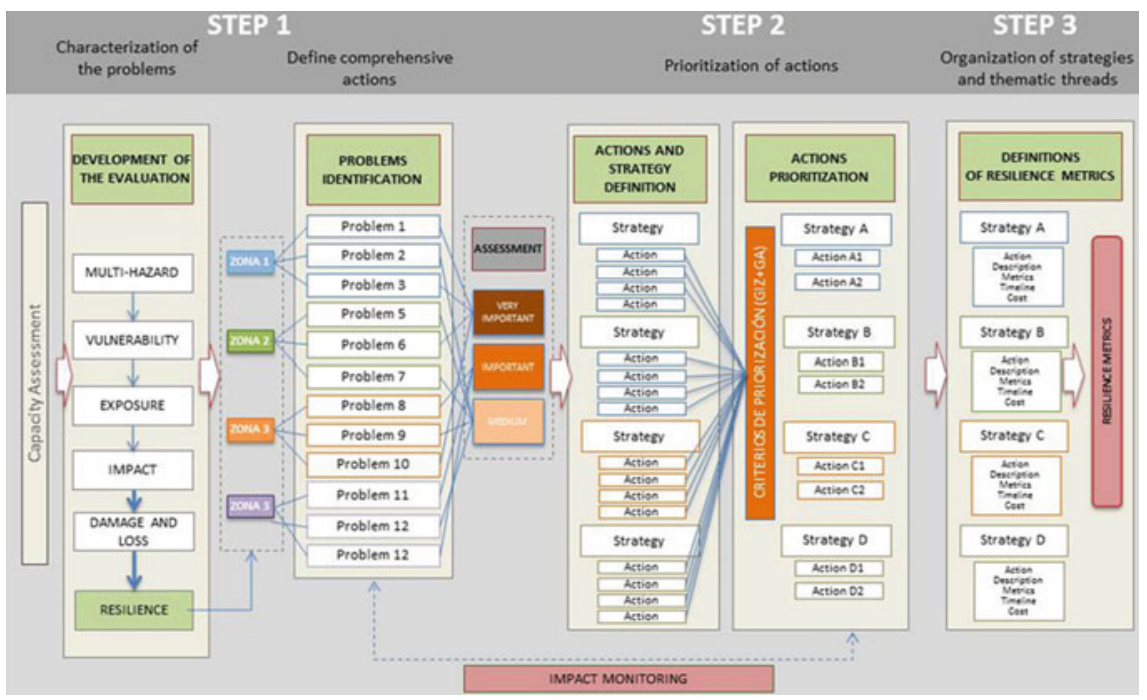

Fig. 14.3 Methodological framework for the definition of actions and strategies 
multi-hazard assessment generated by different sources of information to identify areas of greatest latent danger; a vulnerability assessment (physical and social); an exposure assessment (physical and social); the impact analysis of Hurricane Odile, including the identification of damages and economic losses; and a resilience evaluation, including disaster prevention and response capacities in the city.

2. Identification and appraisal of challenges (14.3.3). Technical Mainstreaming. Having identified the baseline conditions the key challenges are identified based on the predetermined geographic organization of the city (zones).

3. Definition and prioritization of actions (14.3.3). Institutional Mainstreaming. Specific actions are defined for each challenge and each is evaluated through a series of filters and prioritization criteria. The objective is to identify the key, priority actions that will contribute the most to the development of integral, multi-sector resilient strategies.

4. Organization of actions by thematic grouping and definition of strategies (14.3.3). Institutional and Educational Mainstreaming. Once all the actions have been evaluated by the prioritized they are organized into specific thematic groupings based on implementation synergies, interdependencies and other interrelated benefits.

\subsubsection{Resilience Analysis}

Exposure and impact analysis allow the dimensioning of natural hazard effects. However, they do not indicate whether a city has the capacity to resist, adapt, cope and recover from the negative effects of that hazard. For this reason, it is necessary to approach the concept of resilience in an integral way, evaluating the dynamic conditions of the behavior of the communities and the infrastructure that support them in order to improve the skills and capacities needed to weather the impacts from a disaster.

In the case of La Paz, Odile's presented a highly relevant opportunity to fully assess the resilience of both the communities and the surrounding physical infrastructure.

The resilience analysis considered hurricane Odile as a trigger event and addressed resilience in a cross-sectoral way, incorporating the following considerations: (1) how the hazard was addressed by city officials, (2) what type of response actions were put into action to address the event, and (3) how the city recover from the event.

Resilience is traditionally measured through numerical indicators and metrics. However, one of the most significant challenges in defining strategies and actions to improve resilience is the incorporation of a spatial component. The spatial element permits the identification of specific neighborhoods, communities and infrastructure that will require direct intervention. For this reason, the resilience analysis developed for La Paz has the distinctiveness of being designed to explore resilience not only through quantitative methods but also through the incorporation of a 
geographic component. Through this analysis, specific areas of high or low resilience can be identified and directly associated with specific conditions or triggers. This particular approach, was shaped on the resilience evaluation by Cutter et al. (2008), present resilience as a dynamic process dependent on antecedent conditions, the disaster's severity, time between hazard events, and influences from exogenous factors.

The analysis developed was based on a geographical database generated from information obtained from official sources (INEGI) and supplemented with data obtained from secondary sources, prior evaluations and interviews with local officials. The data collected was systematized in a Geographic Information System (GIS), creating a digital environment for the assessment. The geostatistical evaluation was elaborated through an analysis of geographical spatial statistics, which required the segmentation of the city in a grid of $50 \times 50 \mathrm{~m}$ cells. Each cell was assigned a numerical value that represented the factor being evaluated. The use of geostatistical analysis permitted the identification of a resilience value and therefore pinpoint areas of lower resilience, as well as the factors or sectors that structurally contributed to the inherent resilience of the city and its communities. Additionally this approach allowed for the creation of a general spatial index of resilience capacities for each sector, allowing the visualization of the behavior and spatial distribution of the resilience dynamics.

Each zone in the city was further explored based on the population's access to health, emergency and support services (e.g. hospitals, shelters, etc.). The accessibility assessment was developed through the analysis and quantification of spatial networks, which analyzed the route and travel time from each housing area in the city to the specific points identified for emergency and support services. The final product identified the residential areas with greater difficulty to access support and emergency services during an emergency. For example, the results in La Paz show that the southern communities have the greatest difficulty accessing or receiving emergency support.

When comparing the maximum and minimum values from the results of the resilience capacities spatial analysis, the emergency infrastructure and the health service sector resulted in the lowest values for the following reasons:

- Medical centers have a low capacity (number of beds and doctors per capita).

- Shelters lack sufficient medical capabilities.

- Access to health services and shelters are limited in flood scenarios.

Although the city provides ample coverage of basic services $(77.91 \%$ of the population has access to electricity, water and sewer service according to INEGI), accessibility and coverage in the southern communities of La Paz is a priority issue. The access to health and emergency services is dire especially in flood scenarios due in most part from the potential isolation of the zone due to its geographic location south of the city center and the lack of services to support this part of the city.

A map for each of the services analyzed was created to visualize the results of the spatial-sectoral resilience capacity analysis: spatial patterns clearly show that the 


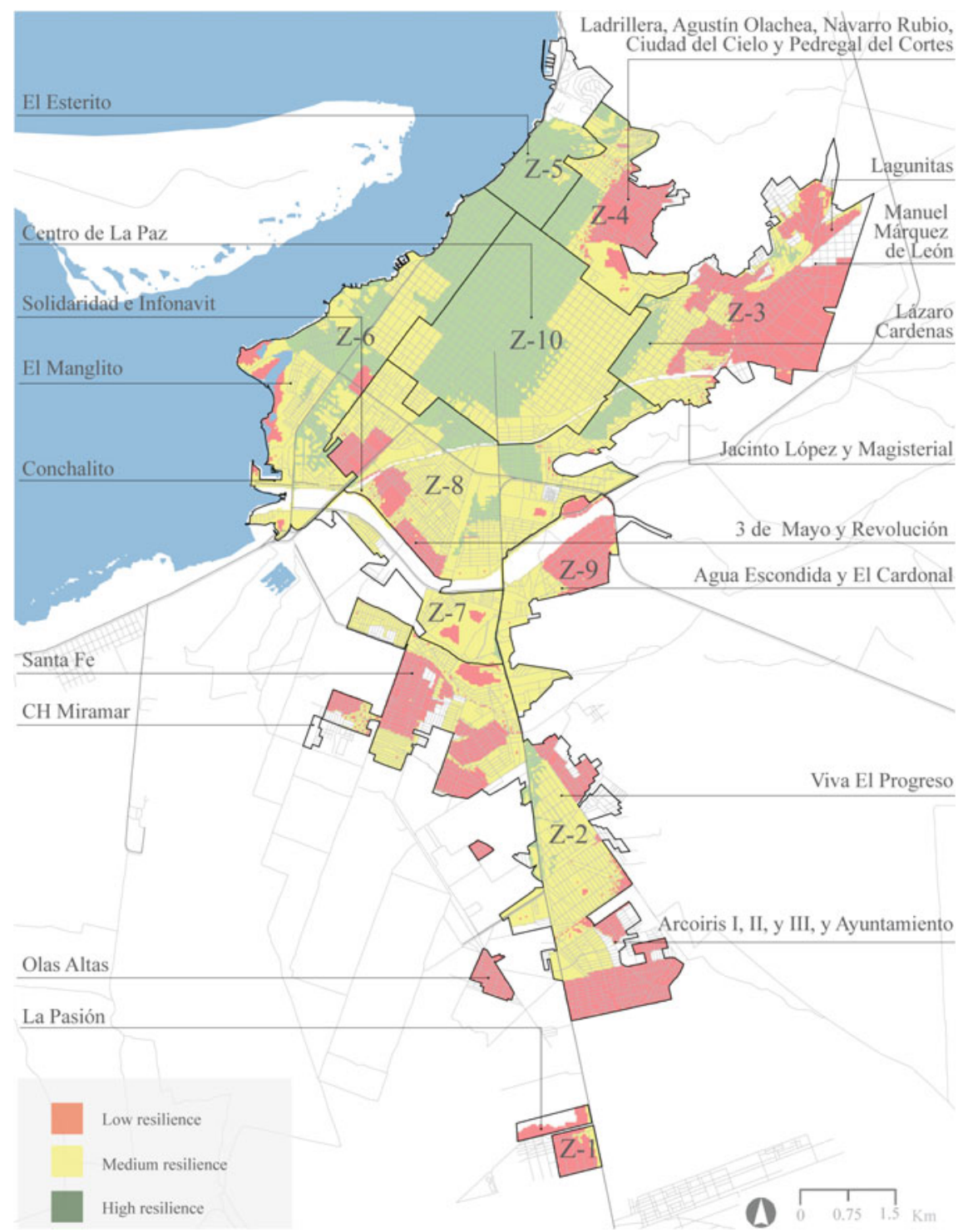

Fig. 14.4 La Paz, Mexico. Resilience capacity map: low (red), average (yellow), high (green)

locations with the least capacity for resilience are located in peripheral areas of the city. The city center (Z-10) presents the conditions of greatest resilience for urban development (Fig. 14.4). In contrast the peripheral areas (Z-1, Z-3, Z-4, Z-9) have the lowest resilience values. It is important to consider this evaluation, given the urban growth pattern of the city, which has been expanding during the last twenty years, from a compact urban model to one of urban sprawl. 
Authorities should consider these resilience patterns, in addition to other factors (e.g. provision of services, environmental impact, etc.) and the consequences that arise if they continue to allow the city to grow in this manner. On the other hand, they must also comply and enforce adequate construction standards and environmental measures necessary to maintain and raise the level of resilience. For example Zones 1, 3, 4 and 9 are shown to have the lowest capacity to prevent and respond to emergencies. During hurricane Odile zone 9 (Agua Escondida) experienced few impacts however, it received low resilience value for it mostly comprised of informal and marginalized communities. Zones 1, 3 and 4 registered the highest number of impacts to housing, as they are in multi-hazard areas and lack access to emergency services, which means these communities are in high impact areas and have little capacity to cope.

The city center (Z-10) has a high capacity to cope with events caused by natural hazards. Despite the damages to the road networkin this zone during Odile, its access to basic and emergency services remained intact, for it is not in a high multi-hazard area and all of its sectors have an integrated prevention and response actions plan. On the other hand, zones 5 and 6, which include areas with the majority of the hotels and services of the city, proved to have a medium to high response capacity. It should be noted that the study is based on the impacts and response actions to hurricane Odile, and in this case, there was no significant damage in these zones. However, this area is highly vulnerable to both storm surge and coastal flooding.

\subsubsection{Mainstreaming Analysis}

The main challenges identified for the city were organized and evaluated considering the results of the resilience analysis, which included: the multi-risk analysis, the resilience analysis, the previous works completed for the ESCI initiative and the impact assessment for hurricane Odile. Additional analysis was done to evaluate the priority areas identified as part of the resilience analysis and the priority areas identified as part of the resilience analysis and the priority areas identified by the local government and civil society groups. Different layers of information were analyzed to observe the spatial overlaps that occur between the different perspectives and to identify the neighborhoods (colonias) that should be considered priorities, having incorporated broader perspectives from different local constituencies. Once identified, these prioritized areas were linked to the geo referenced damages caused by hurricane Odile in order to verify the most prone areas. Of the 109 specific impacts reported to road network, 2 occurred in vulnerable areas mapped by the city council, and 8 occurred in vulnerable areas reported by civil society.

The subsequent actions and strategies developed were identified through the previous mentioned methodological framework. 


\section{Identification and Appraisal of Challenges-Technical Mainstreaming}

In order to better understand and explore the role of resilience planning can have upon the city the most important and critical challenges were identified. These challenges were taken from the different components from the resilience analysis as well as directly from city officials and key civil society groups. As a result 22 challenges were identified in addition to the geographic reach of each issue. The challenges were categorized into two main groups: problems specific to a zone or area of the city (e.g., zone 10, or neighborhood X), or problems that affect the entire city (e.g. water shortage). Through the examination and analysis of these spatial patterns, the relationships with each geostatistical zone of the city were explored.

\section{Definition and Prioritization of Actions-Institutional Mainstreaming}

For each of the 22 challenges specific actions were developed to address the issues at hand. In preparation for this exercise, an extensive review of projects and prior evaluations of the related issues was carried out to generate a list of actions or interventions vetted by previous studies. A total of 81 strategies, actions or interventions were noted, organized by sector and reviewed with the Resilience Committee for further verification.

Using the information gathered for the challenges, geographic and quantitative, as well as the corresponding strategic interventions, a total of 29 actions were generated in response to the 22 challenges. During this identification and evaluation process, the team used the information collected during multiple workshops with local stakeholders and meetings held with the Resilience Committee. The final actions were identified based on the following set of considerations described below, which would facilitate the implementation and feasibility of the proposed actions.

- the level of vulnerability in the location where the action is being proposed and its relationship to other hazards

- the effects of climate change and other hazards on the action

- clear identification of the stakeholders that should be involved or the relationships they have with other implementing organizations

- the monitoring and evaluation processes for the identified actions

- direct relationship or link with other identified actions or current efforts

- geographic scale of the action (some measures need to be applied at the city scale, others at a site scale)

- length and duration of the implementation phase of the action

The list (Table 14.1) represents an example of the challenges and corresponding actions, however the final list was further refined through a set of filters in order to identify the most relevant actions to help improve the resilience of the city.

Once the actions were defined, characterized by sectors geographical located, a prioritization scheme based on a multi-criteria analysis was developed to identify the most relevant actions to implement as part of the resilience strategy. A total of 13 criteria were used for this adaptation prioritization phase. The first 10 key criteria from the criteria of the prioritization framework used by GIZ (2015) called "Methodology of prioritization of adaptation measures" the team selected 10 key 
Table 14.1 List of problems organized by thematic axis with their corresponding actions

\begin{tabular}{|c|c|c|}
\hline Category & Challenge & Action \\
\hline \multirow[t]{2}{*}{ Energy } & $\begin{array}{l}15 \text { Electric distribution system is } \\
\text { isolated from national lines, its } \\
\text { design makes it vulnerable to } \\
\text { hydro-meteo events }\end{array}$ & $\begin{array}{l}\text { Upgrading electric } \\
\text { transmission and } \\
\text { distribution system }\end{array}$ \\
\hline & 16 Lack of alternative energy sources & $\begin{array}{l}\text { Promote and implement } \\
\text { alternative energy } \\
\text { generation in safe areas }\end{array}$ \\
\hline \multirow{2}{*}{$\begin{array}{l}\text { Communication } \\
\text { and transportation }\end{array}$} & 17 Primary road in flood prone areas & Causeway construction \\
\hline & $\begin{array}{l}18 \text { Fiber-optic cable prone to hurricanes } \\
\text { and floods }\end{array}$ & $\begin{array}{l}\text { New fiber-optic undersea } \\
\text { cable from Topolobampo } \\
\text { to La Paz }\end{array}$ \\
\hline \multirow[t]{4}{*}{ Natural areas } & $\begin{array}{l}19 \text { Lack of regulation for urban forestry } \\
\text { location and maintenance }\end{array}$ & $\begin{array}{l}\text { Landscaping strategy to } \\
\text { reduce the heat island } \\
\text { effect and power demand }\end{array}$ \\
\hline & $\begin{array}{l}20 \text { Tree canopy loss increase heat island } \\
\text { effect and vulnerability to natural } \\
\text { hazards }\end{array}$ & $\begin{array}{l}\text { Green corridors } \\
\text { incorporating greenway }\end{array}$ \\
\hline & $\begin{array}{l}21 \text { Coastal dunes alteration increase } \\
\text { flood and erosion threats }\end{array}$ & $\begin{array}{l}\text { Coastal dunes } \\
\text { restoration/stabilization, } \\
\text { and prevention of salt } \\
\text { water intrusion }\end{array}$ \\
\hline & $\begin{array}{l}22 \text { Mangrooves and wetlands loss } \\
\text { expose the city to storm surge and } \\
\text { wind }\end{array}$ & $\begin{array}{l}\text { Coastal protection plan } \\
\text { incorporating } \\
\text { mangroves/wetlands } \\
\text { protection, flood, erosion } \\
\text { and salt water intrusion } \\
\text { prevention }\end{array}$ \\
\hline
\end{tabular}

criteria were adapted from the prioritization framework used by the German Agency for International Cooperation (GIZ) "Methodology of prioritization of adaptation measures" (2015). The rating scale for each criterion was taken from the descriptions outlined in the GIZ's methodological documentation.

The base evaluation criteria were supplemented with three additional filters developed by the GeoAdaptive (GA) team in order to further enrich the evaluation, described as follows:

(1) Resilience filter

- Criteria: The action increases the resilience of the city and minimizes its vulnerability

- Evaluation: Contributes slightly (1), medium (2) or substantially (3)

(2) Financial feasibility filter

- Criteria: The general estimated implementation cost of the action, taking into account projects of a similar scale and complexity.

- Evaluation: \$ (1), \$ (2), \$\$ (3) 
(3) Technical and political viability filter

- Criteria: The action is viable taking into consideration the technical knowledge available in the city and the support of politicians, based on similar projects in the city.

- Evaluation: not viable (1), moderately viable with additional support (2), viable with the technical knowledge available to the city (3)

This final list of 13 criteria was discussed and validated with the Resilience Committee to ensure that the most vital factors were taken into consideration in light of the committee's perspective regarding the importance and applicability of the actions.

All filters, both GIZ and supplementary formulations, were evaluated with an equitable weight.

For the final evaluation, the values of the 13 filters were weighted using the following equation:

$$
A=\frac{1}{n} \times \sum_{t=1}^{n} x_{\mathrm{i}}
$$

Where:

$A$ is the average value of the performance evaluation

$\Sigma$ is the sum of all values

$n$ is the number of variables

$X_{i}$ is the value of each individual variable in the criteria list

$n$ is the number of terms or items evaluated

The evaluation ranks were as follows:

- Between 0 and 1 = Low priority

- Between 1 and 2: Medium priority

- Between 2 and 3: High priority

Several of the final actions are related to urban planning initiatives such as water resource planning, coastal protection and disaster risk reduction strategies. Therefore, through this process, several actions were designed and prioritized to ensure the distribution amongst key sectors, as well as the responsible entities of implementation. Due to this objective, the responsibility for implementing the proposed actions does not lie exclusively with government entities, but involves other stakeholders, including civil society, the private sector and academia.

The application of the filters yielded a total of 20 prioritized actions from of the original group of 29, with actions prioritized for each of the key sectors. The top 20 actions scored evaluations ranging from 2 to 3 , or high priority. These were further analyzed to explore their potential distribution with respect to the sectorial categories associated with each of the problems. It was encouraged that decision makers in La Paz evaluate the incorporation of these actions into existing efforts, given their preventative nature and high prioritization score (Table 14.2). 


\section{Organization of Actions by Thematic Grouping and Definition of Strategies-Institutional and Educational Mainstreaming}

The delineation of multi-sectoral strategies aimed to group or organize the prioritized actions into larger thematic groups that allowed the identification of synergies between the actions, sectors and stakeholders that can facilitate their implementation in a more efficient manner. Each strategy for La Paz was developed considering the involvement of various stakeholders and the linking of different institutions that would contribute to the achievement of the objectives set out by these thematic groups. Likewise, the strategies ensured that there were measures and activities at a variety of scales that assured that there were challenges identified at the local, urban and regional scale. This aspect was particularly important in La Paz because of its location on a peninsula, making it vulnerable to large hydro-meteorological events since it relies on basic infrastructure that is regionally operated (energy, water, transportation).

It was equally important that the multi-sectoral model explicitly indicate the responsibilities of each stakeholder involved. In order to achieve this, each action was linked not only to the various municipal, state and federal government institutions and private and academic stakeholders but also to the tools, actions and projects already proposed or underway, such as those indicated by the PIMUS (Plan Integral de Mobilidad Urbana Sustentable), the PACC-LAP (Plan de Acción de Cambio Climático - La Paz) or proposed by the GIZ.

The prioritized actions were grouped around specific thematic groups by adhering to the following the principles:

- synergy among the actions within the same thematic group

- collaboration between stakeholders and institutions

- sectoral interdependence within the same thematic group

- capture and distribution of shared benefits

- extent or duration of implementation within the same thematic group (some actions are short term, while others are long term)

As a result, 5 key thematic groups were defined, providing a comprehensive base to organize the prioritized 20 actions. The 5 thematic groups are:

- 1: territorial management of natural hazards,

- 2: provision of urban infrastructure and services

- 3: strengthening social and business participation

- 4: institutional risk management

- 5: Integrated management of natural resources

\subsubsection{Results}

The Roadmap and the Resilience metrics were two tools developed as part of the study with the aim to guide and assist the implementation of the prioritized actions. 
Table 14.2 Example of the application of filters to the actions identified for the city of La Paz

\begin{tabular}{|c|c|c|c|c|c|c|c|c|c|c|c|c|c|c|c|}
\hline & \multicolumn{13}{|c|}{ Multi-criteria } & \\
\hline & & \multicolumn{10}{|c|}{ GIZ } & \multicolumn{3}{|c|}{ GA } & \\
\hline & & 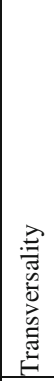 & 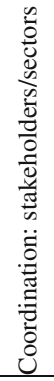 & 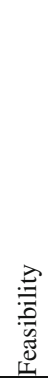 & 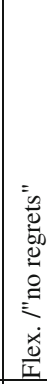 & 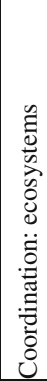 & 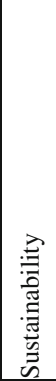 & 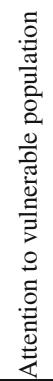 & 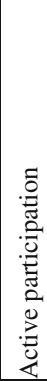 & 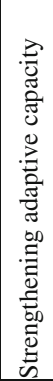 & 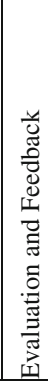 & 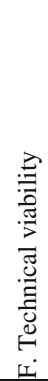 & 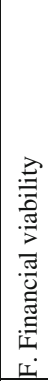 & 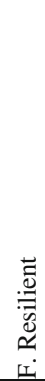 & 氶 \\
\hline \# & Actions & 1 & 2 & 3 & 4 & 5 & 6 & 7 & 8 & 9 & 10 & $\mathrm{~A}$ & $\mathrm{~B}$ & $\mathrm{C}$ & \\
\hline \multicolumn{16}{|c|}{ URBAN PLANNING AND RISK MANAGEMENT } \\
\hline 1 & \begin{tabular}{|l|} 
Include technical \\
standards that integrate \\
hazard, vulnerability and \\
risk maps into plans in \\
order to restrict \\
development in high risk \\
areas and identify \\
alternative programmatic \\
or land uses. \\
\end{tabular} & 3 & 3 & 2 & 2 & 3 & 3 & 3 & 1 & 3 & 3 & 3 & 3 & 3 & 3 \\
\hline 2 & $\begin{array}{l}\text { Relocate housing that is } \\
\text { located in unmitagable } \\
\text { high risk areas to low risk } \\
\text { zones, with access to } \\
\text { basic services. } \\
\end{array}$ & 2 & 3 & 3 & 3 & 1 & 2 & 3 & 2 & 2 & 3 & 3 & 2 & 3 & 3 \\
\hline 3 & $\begin{array}{l}\text { Channelize and install } \\
\text { flood protection } \\
\text { infrastructure to prevent } \\
\text { the flooding of nearby } \\
\text { housing and key } \\
\text { infrastructure. } \\
\end{array}$ & 3 & 3 & 3 & 3 & 1 & 2 & 3 & 3 & 3 & 3 & 3 & 2 & 3 & 3 \\
\hline 4 & $\begin{array}{l}\text { Build stabilization } \\
\text { projects on the edges of } \\
\text { the El Trinfo and El } \\
\text { Cajoncito streams to } \\
\text { reduce erosion and } \\
\text { protect the streambeds. }\end{array}$ & 1 & 3 & 3 & 2 & 1 & 1 & 3 & 3 & 2 & 2 & 2 & 1 & 1 & 2 \\
\hline 5 & $\begin{array}{l}\text { Develop a public } \\
\text { awareness and education } \\
\text { campaigns to deal with } \\
\text { prevention and } \\
\text { preparation when faced } \\
\text { with the threat of natural } \\
\text { hazards. }\end{array}$ & 3 & 3 & 2 & 3 & 3 & 3 & 3 & 2 & 3 & 3 & 3 & 2 & 3 & 3 \\
\hline
\end{tabular}


They contributed to the implementation by defining the general scope of the prioritized actions within a strategy, the dimensioning of activities, approximate costs, and the potential impacts of each action.

The implementation success of these actions will depend on the coordination and collaboration between stakeholders and the potential need to create temporary alliances to facilitate the process.

Given that resilience depends on a continuous process between government, private sector and civil society, it will require the development and sustainment of a continuous dialogue where adjustments and improvements in the prioritized actions are discussed and explored given the current political, financial, and temporal context as well as environmental conditions.

\section{The Road Map}

The Road Map outlines the prioritized interventions or actions, which were organized into five thematic strategies (Table 14.3). Specific resilience metrics were identified for each action that can be used to monitor the implementation of the action, the period of implementation, the expected impact, and the approximate implementation cost for each project.

As a complement to the Road map, a locator map was included that spatially identified the prioritized actions. However, not all actions were identified geographically because some are programmatic in nature or refere to training and should be applied or available city-wide and were not specific to a particular area or geographic location.

The approximate projected costs were provided for each action as a reference. These were determined through research of other similar projects in the region or Mexico and by interviews with professionals or government representatives. However, looking at the distribution of the financial burdens and responsibilities of the programmed actions, it is noticeable that the urban management strategies represent the most relevant and widespread of the projected investments.

The average execution period for the actions varies; however, most fall within the medium term (approximately 1 year), providing an opportunity for the identification of financing mechanism, and could be initiated soon after the completion of the study in order to take advantage of the momentum generated from the project, maximizing its potential for implementation.

It should be noted that the distribution of the financial costs associated with the execution of the actions was also carefully considered in this study.

$32 \%$ of the final actions were identified as requiring Municipal level intervention. More than $50 \%$ of the 5 actions prioritized under the "Urban Planning and Risk Management" strategy also required financial support at the municipal level. This cost, although a large undertaking for the Municipal government, represents an opportunity for local authorities to demonstrate leadership in the public sector and improve the internal capacities of the municipal staff.

Given the fact that the initial stages of the proposed projects will represent a greater use of resources, the municipal government may consider requesting assistance in terms of management of the respective federal authorities, or request technical and economic assistance through international cooperation. The lowest 
Table 14.3 Road Map-Summary table of the costs for the 5th thematic axis: "Integral management of natural resources"

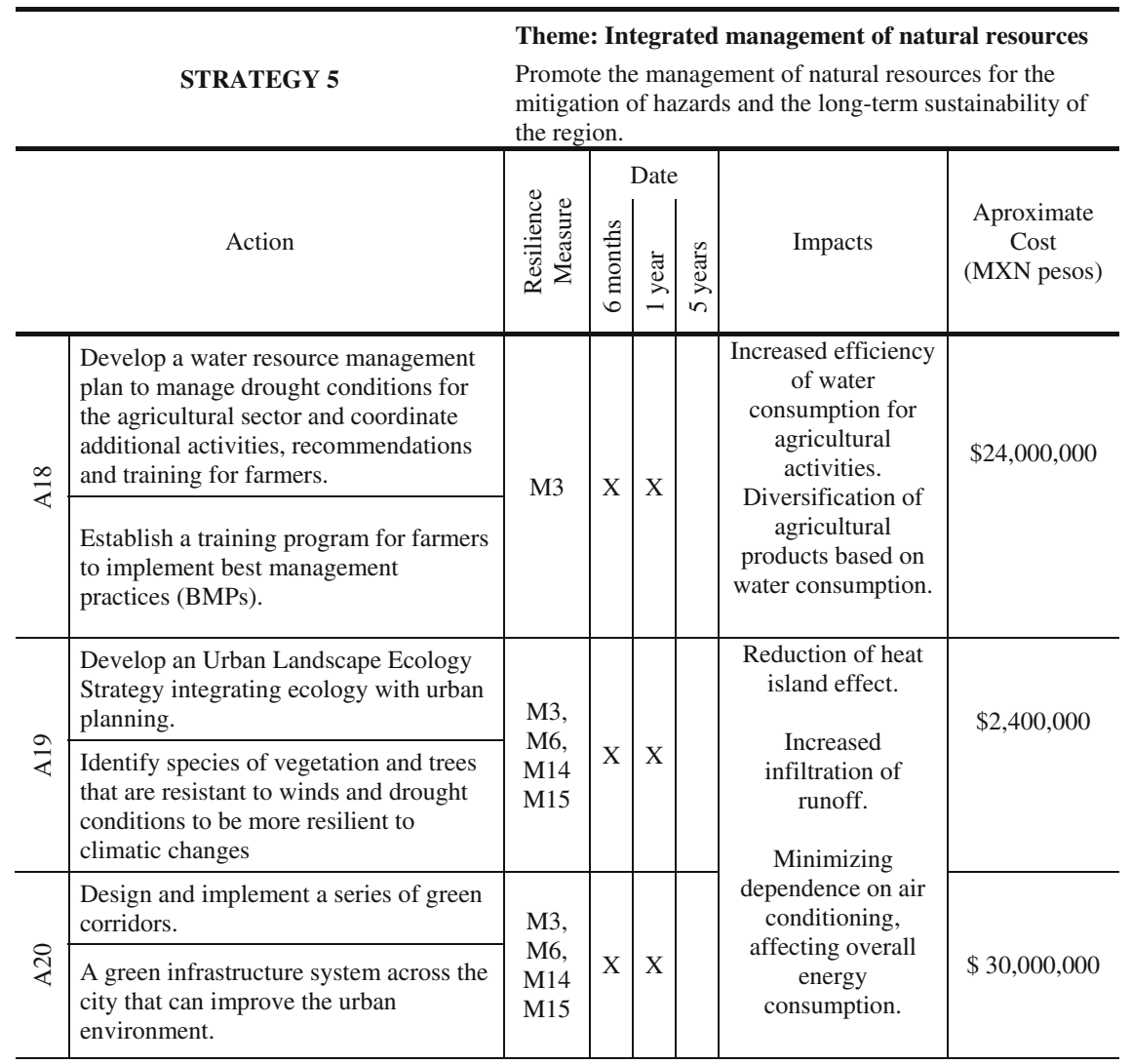

economic costs are represented by the "Strengthening social and business participation in emergency management" with MXN\$598,856 pesos and the "Provision of urban infrastructure and services" with 2,940,000 pesos. These two categories represent an area of opportunity to increase the city's resilience, since they can help create change in the behavior and culture of La Paz's residents through education and training programs. Other strategies such as the "Integrated management of natural resources" (MXN\$56,400,000 pesos), have a much higher implementation costs due to the complexity and scale of the efforts required.

\section{Resilience Metrics}

It is fundamental to improve and guide the efforts of decision-makers and leaders of civil society to manage and assess the implementation and impact of resilience focused projects. Monitoring and evaluation systems are essential elements for assessing the performance of actions and interventions in the light of minimizing 
risk and improving resilience. As a response, a series of resilience metrics were designed to evaluate of the state of the city in reference to resilience and measure the effect of current and future interventions.

More than 300 existing indicators for resilience, vulnerability and risk were examined through a literature review (including global systems and tools available to decision makers, for example indicators from UNISDR, IDB, World Bank and the Rockefeller Foundation). Indicators were selected and developed with quantifiable and evaluable metrics from easily accessible and periodically generated data. The final set of indicators were selected considering expert technical knowledge and the following characteristics:

- Applicability to local conditions in La Paz and other similar cities in the region

- Prevalence in the literature

- Indicators that address multiple components of urban resilience (including risk)

- Ability to be supervised by the Resilience committee

- Relevance to infrastructure and social capacities to address threats

- Availability of data needed to support indicators in La Paz.

A total of twenty-one resilience metrics were developed to form the resilience assessment matrix. These indicators cover both the socio-organizational capacities and the functioning and performance of infrastructure and urban systems, in relation to the occurrence of natural hazards.

The metrics are divided by topics to facilitate its application:

- 1: Access and availability to basic services and infrastructure.

- 2: Health and social welfare.

- 3: Risk management and emergency management.

- 4: Damage and impacts in emergencies.

In order to facilitate the indicator evaluation, a traffic light assessment was developed, using a benchmark scale generated from global (World Bank) and local standards (reference indexes in Mexico and in Baja California Sur). The proposed metrics allow the use of both statistical and geographical information periodically provided by official institutions such as INEGI or the city government, which generate the necessary information for evaluation in a reoccurring and financial sustainable way. The traffic light assessment facilitates the evaluation through a clear and simple system (light grey, grey, black) that can be easily interpreted and would provide a baseline or reference for future evaluations (Tables 14.4 and 14.5).

Table 14.4 Classification of the traffic light assessment

Meets or exceeds resilience and sustainability standards

Has gaps in its resilience measure

Below the minimum standard 
Table 14.5 Resilience metrics focused on the access and availability to basic services and infrastructure

\begin{tabular}{|c|c|c|c|c|c|c|}
\hline \multirow[t]{2}{*}{ No. } & \multirow{2}{*}{$\begin{array}{l}\text { Resilience } \\
\text { Measure }\end{array}$} & \multirow[t]{2}{*}{ Description } & \multicolumn{3}{|c|}{ Thresholds A } & \multirow{2}{*}{$\begin{array}{c}\text { LaPaz } \\
\text { BCS }\end{array}$} \\
\hline & & & $\begin{array}{l}\text { Light } \\
\text { Grey }\end{array}$ & Grey & Black & \\
\hline M1 & $\begin{array}{l}\text { Potable } \\
\text { water } \\
\text { coverage }\end{array}$ & $\begin{array}{l}\text { Percent of houses } \\
\text { with access to } \\
\text { potable water. }\end{array}$ & $80-100 \%$ & $60-80 \%$ & $<60 \%$ & $\begin{array}{l}97.9 \% \\
\text { ICES } 2012\end{array}$ \\
\hline M2 & $\begin{array}{l}\text { Efficiency } \\
\text { in water } \\
\text { use }\end{array}$ & $\begin{array}{l}\text { Water } \\
\text { consumption per } \\
\text { capita }\end{array}$ & $55-90$ & $\begin{array}{l}37-55 \text { y } 90- \\
110\end{array}$ & $<37 \mathrm{y}>110$ & $\begin{array}{l}82.54 \mathrm{~m} 3 / \\
\text { person / } \\
\text { year ICES } \\
2012\end{array}$ \\
\hline M3 & $\begin{array}{l}\text { Availability } \\
\text { of water } \\
\text { resources }\end{array}$ & $\begin{array}{l}\text { Net water balance } \\
\text { (internal and } \\
\text { external resources) }\end{array}$ & $\begin{array}{l}>0 \\
\text { MMC/ } \\
\text { year }\end{array}$ & $\begin{array}{l}<0 \text { MMC / } \\
\text { year, with } \\
\text { conservation }\end{array}$ & $\begin{array}{l}<0 \mathrm{MMC} / \\
\text { year, without } \\
\text { conservation }\end{array}$ & $\begin{array}{l}<0 \text { million } \\
\mathrm{m} 3 / \text { year }\end{array}$ \\
\hline M4 & $\begin{array}{l}\text { Electricity } \\
\text { coverage }\end{array}$ & $\begin{array}{l}\text { Percent of houses } \\
\text { with electric } \\
\text { service. }\end{array}$ & $90-100 \%$ & $\begin{array}{l}\text { plans } \\
70-90 \%\end{array}$ & $\begin{array}{l}\text { plans } \\
<70 \%\end{array}$ & $\begin{array}{l}98 \% \text { ICES } \\
2012\end{array}$ \\
\hline M5 & $\begin{array}{c}\text { Technology } \\
\text { and } \\
\text { Communic }\end{array}$ & $\begin{array}{l}\text { Percentage of } \\
\text { houses with cell } \\
\text { phones. }\end{array}$ & $90-100 \%$ & $80-90 \%$ & $<80 \%$ & $\begin{array}{l}\text { 74\% ICES } \\
2010\end{array}$ \\
\hline & $\begin{array}{c}\text { ation } \\
\text { Coverage }\end{array}$ & $\begin{array}{l}\text { Percent of houses } \\
\text { with internet. }\end{array}$ & $50-100 \%$ & $40-50 \%$ & $<40 \%$ & $\begin{array}{l}36 \% \text { ICES } \\
2010\end{array}$ \\
\hline M6 & $\begin{array}{l}\text { Percent of } \\
\text { managed } \\
\text { runoff. }\end{array}$ & $\begin{array}{l}\text { Percent of } \\
\text { vegetation with } \\
\text { respect to the } \\
\text { urban footprint }\end{array}$ & $>40 \%$ & $30-40 \%$ & $<30 \%$ & N/D \\
\hline
\end{tabular}

\subsection{Conclusions}

The planning and development of a resilient society requires a complex and highly integrated approach. Establishing processes and analysis that identify timely and tangible strategies that respond to the challenges posed by climate change and natural hazards continue to be an unknown issue for many cities.

Multiple discussion points emerge when carrying out a study of this nature. The methods, approaches, and evaluation instruments used are rapidly evolving. On the other hand, studying resilience in the context of the recent impact of a hurricane such as Odile, poses even more significant challenges because of the availability of information and data that is sensitive to social, environmental and economic constraints.

The participation of local stakeholders is fundamental to the success of this process, particularly in the institutional and educational mainstreaming phases. The development of a participatory and knowledge-generating process rather than an advisory one is a critical distinction that must be highlighted.

A stakeholder analysis is a crucial first step to identify influential participants and key stakeholders of the city, who can form part of a working consultative group (Resilience Committee). The formation of the group can help ensure the early involvement and support from key members of the city, as well as a better transition between recommendations and the implementation of projects to ensure a "live" final 
product. The members of the group should be key members representing the different levels of government, the institutional organizations from each sector involved, as well as from civil society and the private sector. It is necessary to emphasize the level of commitment required by the Committee at the beginning, throughout and after the study to ensure the validity and follow-up of the implementation and evaluation processes. The formation of this group is essential to the development and improvement of the local capacity of local resilience experts in the city (technical mainstreaming).

In addition to local stakeholder knowledge it is fundamental to include and build upon the knowledge and results from prior studies and efforts. The incorporation of existing technical information and data helped the alignment and contextualization of the results and the formulation of actions that are verified with previously validated information (technical mainstreaming).

The compilation of georeferenced data (GIS, .kml, etc.) was essential for the spatial assessment, the visualization of challenges and proposals, and the analysis of resilience capabilities. It is recommended to coordinate and train collaborators from various local institutions in the collection of information through the use of free platforms such as Open Street Maps and Quantum GIS. This will allow their involvement from the beginning of the study, as well as the generation of local capacities.

The experiences gained in the area of resilience and risk management reveal that no sector or entity is capable of addressing all aspects of response and adaptation. Resilience and risk management are multi-sectoral issues that require a systemic and holistic perspective. This requires the development of processes and analyzes that recognize the interdependencies between sectors and formulate actions that encompass and motivate a multi-sector, transdisciplinary and multi-institutional collaboration. Key to achieving this goal is to have representatives from different sectors in discussions and analysis that recognize their interactions and synergies.

\section{References}

ADPC. 2010. Mainstreaming disaster risk reduction. Book 4, urban governance and community resilience guides. Bangkok: ADPC.

Bahadur, A., and T. Tanner. 2013. Policy climates and climate policies: Analysing the politics of building urban climate change resilience. Urban Climate 7: 20-32.

Becker-Birck, C., J. Crowe, J. Lee, and S. Jackson. 2013. Resilience in action: Lessons from public-private collaborations around the world. Boston, US: Meister Consultants Group Inc.

Benson, C. 2009. Mainstreaming disaster risk reduction into development: Challenges and experience in the Philippines. Geneva: ProVention.

Bettencourt, S. et al. 2006. Not if, but when: Adapting to natural hazard in the Pacific Islands region: A policy note. World Bank Policy Note. Washington, D.C.: World Bank.

CENAPRED. 2015. Ciclones tropicales (Huracanes). http://www.atlasnacionalderiesgos.gob.mx/ index.php/riesgos-hidrometeorologicos/ciclones-tropicales-huracanes.

Cutter, S., L. Barnes, M. Berry, C. Burton, E. Evans, E. Tate, and J. Webb. 2008. A place-based model for understanding community resilience to natural disasters. Global Environmental Change 18 (4): 598-606. doi:10.1016/j.gloenvcha.2008.07.013.

GIZ. 2015. Propuestas de temas y proyectos GAU prioritarios. Anexo 6.

Harris, K., and A. Bahadur. 2014. The case of Vanuatu: Integration of disaster risk management, environment and climate change. In Vanuatu: Integration of disaster risk management, environment and climate change in Vanuatu. London: ODI. 
INEGI. 2010. Censo de población y vivienda 2010 del Instituto Nacional de Estadística y Geografia.

Jahan, R. 1995. The elusive agenda: Mainstreaming women in development. London: ZED Books.

La Trobe, S. 2005. Mainstreaming disaster risk reduction: A tool for development organisations. Australia: TEARFUND.

Mackay, F., and Bilton, K. 2003. Learning from experience: Lessons in mainstreaming equal opportunities. Scottish Executive Social Research.

Munich Re. 2015. NatCat SERVICE Loss database for natural catastrophes worldwide.

Oates, N., et al. 2011. The mainstreaming approach to climate change adaptation: Insights from Ethiopia's water sector. ODI Background Note. London: Overseas Development Institute.

Pelling, M. and A. Holloway. 2006. Legislation for mainstreaming disaster risk reduction. Middlesex: Tearfund archive www.preventionweb.net/english/professional/publications/v. php?id=1198. Accessed: September 272013.

Pelling, M., and B. Wisner. 2009. Reducing urban disaster risk in Africa. In Disaster risk reduction: Cases from urban Africa, ed. M. Pelling, and B. Wisner. London: Routledge.

Pervin, M., et al. 2013. A framework for mainstreaming climate resilience into development planning. London: IIED.

Schipper, L., and M. Pelling. 2006. Disaster risk, climate change and international development: Scope for and challenges to integration. Disasters 30 (1): 19-38. doi:10.1111/j.1467-9523. 2006.00304.x.

Scott, Z., and M. Tarazona. 2011. Study on disaster risk reduction, decentralization and political economy: Decentralization and disaster risk reduction. Global Assessment Report 2011. Geneva: UN Office for DRR.

UNDP-UNEP. 2011. Mainstreaming climate change adaptation into development planning: A guide for practitioners.

UN-Habitat. 2016. Urbanization and development: Emerging futures. In World cities report 2016. Nairobi: UN-Habitat.

UNISDR. 2015. Sendai framework for disaster risk reduction 2015-2030. Geneva: UNISDR.

UNISDR. 2016. Panel 3 Disaster risk reduction in public finance planning and investment, Reunión ministerial y de autoridades de alto nivel sobre la implementación del marco de Sendai para la reducción del riesgo de desastres 2015-2030 en las Américas. http://eird.org/ ran-sendai-2016/eng/sessions/session-1/S1P3-Session-1-Panel-3.pdf.

Williams, G. 2011. Study on disaster risk reduction, decentralization and political economy: The political economy of disaster risk reduction. In Global assessment report 2011. Geneva: UN Office for DRR.

World Bank. 2016. Shock waves, managing the impacts of climate change on poverty. Washington DC: The World Bank.

Open Access This chapter is licensed under the terms of the Creative Commons Attribution 4.0 International License (http://creativecommons.org/licenses/by/4.0/), which permits use, sharing, adaptation, distribution and reproduction in any medium or format, as long as you give appropriate credit to the original author(s) and the source, provide a link to the Creative Commons license and indicate if changes were made.

The images or other third party material in this chapter are included in the chapter's Creative Commons license, unless indicated otherwise in a credit line to the material. If material is not included in the chapter's Creative Commons license and your intended use is not permitted by statutory regulation or exceeds the permitted use, you will need to obtain permission directly from the copyright holder.

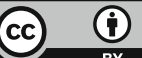

